\title{
Dynamic Characteristics of the Steam Accumulator Charging and Discharging
}

\author{
Peizhi Yang*, Xia Hu and Gang Liao \\ School of Energy Science and Engineering, Central South University, Changsha, Hunan province, 410083, P R China \\ *Corresponding author:yang_peizhi@mail.csu.edu.cn
}

\begin{abstract}
The method of numerical simulation is used to study the charging and discharging process of steam accumulator. By analyzing the charging and discharging thermal process of steam accumulator, establishing the mathematical model and using MATLAB software to simulate the solution, the dynamic characteristic curves of charging and discharging are obtained, and the charging and discharging conditions of the steam accumulator are defined. This research has an important significance in the design and application of the steam accumulator.
\end{abstract}

Keywords. Steam accumulator; Charging characteristics, Discharging characteristics, Numerical simulation.

\section{Introduction}

Energy crisis has become an important issue in the world, severe crisis has put forward a severe warning to mankind. Based on this energy situation, energy saving technology has been referred to an unprecedented height. Steam accumulator is a bridge which can connect steam generators and consumers smoothly, it can give supply and demand sides continuous and stable steam balance, so as to maintain the system running load balance, improve the combustion efficiency and save energy. With the continuous adjustment of China's energy policy and the continuous development of energy saving, steam accumulator will be paid more and more attention, and it will be widely used in industrial enterprises. Now steam accumulator has been widely used in iron and steel industry, power supply and daily necessities production (such as sugar refining, brewing, chemical, printing and dye works) and other industry, and it has achieved good economic benefits.

The dynamic and static characteristics of steam accumulator directly affect the economy and safety of the system; some scholars have carried on the related research. The operating characteristics of steam accumulator were studied by using numerical simulation method [1-5],a thermal test system of a small steam accumulator is established in Ref.[6], and the experimental study of the charging and discharging characteristics of the horizontal steam accumulator is carried out the dynamic process of the water space in the discharging process of the steam accumulator is analyzed by using the equilibrium model and Euler algorithm [7], a non-equilibrium numerical model is used to analyze the characteristics of the steam accumulator charging and discharging [8], and the effect of the inlet steam enthalpy on the change of the water content and the water level is studied. According to the analysis of the steam accumulator charging and discharging, the steam accumulator's mathematical model is established based on the assumption that the water and steam in the vessel in thermal equilibrium, using Matlab mathematical calculation software to write a program to simulate charging and 
discharging process and to analyze the simulation results of different control modes. The conclusion of this paper has certain significance for the design and application of the thermal storage system.

\section{Establishment of mathematical model}

The operation of steam accumulator includes two processes: charging and discharging, the process of charging, i.e. the saturated steam or superheated steam, which from the steam source, inflows into the container; the process of discharging, i.e. the pressure of saturated water in the steam accumulator drop till evaporate, and the released steam provide to the user. According to the thermodynamic characteristics of charging and discharging process, the mathematical model of the steam accumulator is established.

\subsection{Basic hypothesis}

Steam accumulator is divided into water space and steam space, In order to simplify the analysis, the following assumptions are given for the working process of steam accumulator:

(1)At any time, the state parameters of the water space and the steam space, which are the pressure of the steam space corresponding to the saturated liquid and saturated vapor, are uniform and in the state of the thermal equilibrium;

(2)Ignore the power of steam through the vessel wall and the heat dissipation to the environment;

(3) The steam, which released in the exothermic process, is saturated steam;

(4)The density of water is constant, and the density of water vapor is determined by the state equation of ideal gas $\mathrm{P}=$ $\mathrm{RT}$.

\section{2 .Mathematical model}

The calculation and analysis of the steam accumulator charging or discharging, the model used is shown in Fig.1.At a certain moment, the mass of saturated water in the heat accumulator is $M_{w}$, Specific enthalpy is $h_{w}$, the mass of saturated water vapor is $M_{s}$, Specific enthalpy is $h_{s}$; The high temperature and high pressure steam mass flow, which is used in the process of charging, is $m_{1}$, specific enthalpy is $h_{1}$, transient outlet steam mass flow during discharging process is $m_{2}$, specific enthalpy is $h_{2}$, the transient rate of evaporation of water inside the accumulator is $m_{3}$,specific enthalpy is $h_{3}$.

According to the above model, the following balance equations are obtained:

Water space and steam space mass balance:

$$
\begin{aligned}
& \frac{d M_{w}}{d t}=m_{1}-m_{3} \\
& \frac{d M_{s}}{d t}=m_{3}-m_{2}
\end{aligned}
$$

Water space and steam space energy balance:

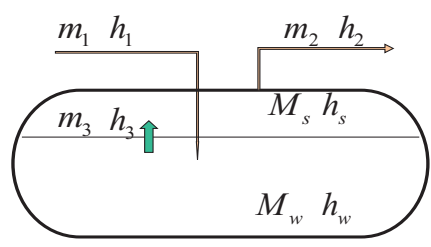

$$
\frac{d\left(M_{w} h_{w}\right)}{d t}=m_{1} h_{1}-m_{3} h_{3}
$$

Fig.1. Schematic of steam accumulator

$$
\frac{d\left(M_{s} h_{s}\right)}{d t}=m_{3} h_{3}-m_{2} h_{2}
$$


The calculation of charging and discharging process can use Eqs.(1) - (4),in the system that the steam accumulator parallel with steam source[9], the mass of charging process at the mathematical model is calculated as $m_{2}=0($ during discharging process, the mass is calculated as $\mathrm{m}_{1}=0$ ).

\section{Numerical solution}

\subsection{Characteristics of charging process of steam accumulator}

According to the above mathematical model, the charging process of the steam accumulator is simulated by using MATLAB software [10].Heat steam from the steam source, which the temperature and pressure parameters have been determined, is the saturated steam or superheated steam, and its pressure is higher than the pressure in the vessel over the final charging state. Iterative calculation of time step is $\Delta t$, the volume of the steam accumulator is $V$, the thermal vapor pressure is $p_{0}$, temperature is $T_{0}$, specific enthalpy of $h_{0}$.In the $\Delta t$ time, the mass flow rate of the hot steam is a constant, i.e. $m_{0}$, suppose the volume of water at a certain time is $V_{1}, p_{1}$ and $T_{1}$ are the pressure and temperature, respectively, $h_{w 1}$ and $h_{s 1}$ are the specific enthalpy of water and steam, respectively, $\rho_{w 1}$ and $\rho_{s 1}$ are the density of water and steam, respectively; After $\Delta t$ time, the volume of water is $V_{2}$, pressure is $p_{2}$ and temperature is $T_{2}, h_{w 2}$ and $h_{s 2}$ are the specific enthalpy of water and steam, respectively, $\rho_{w 2}$ and $\rho_{s 2}$ are the density of water and steam, respectively.

After the steam accumulator charging $\Delta t$ hours, the following equations are obtained.

Mass balance equation:

$$
m_{0} \Delta t+\rho_{s 1}\left(V-V_{1}\right)+\rho_{w 1} V_{1}=\rho_{s 2}\left(V-V_{2}\right)+\rho_{w 2} V_{2}
$$

Energv balance equation:

$$
m_{0} h_{0} \Delta t+\rho_{s 1} h_{s 1}\left(V-V_{1}\right)+\rho_{w 1} h_{w 1} V_{1}=\rho_{s 2} h_{s 2}\left(V-V_{2}\right)+\rho_{w 2} h_{w 2} V_{2}
$$

The enthalpy of saturated water and saturated steam are calculated according to the method suggested in Ref. [11], they are calculated as:

$$
\begin{aligned}
h_{-} \text {water }(T) & =4.1868 \times(1.001 T-0.01) \\
h_{-} \operatorname{steam}(T) & =2.326 \times\left((0.071533 T-13.08426) \times h_{-} \text {water }(T) \times 0.01\right. \\
& +(0.808956 T+1075.18144))
\end{aligned}
$$

Specific enthalpy of saturated water and saturated steam in Eqs.(5)-(6) can be calculated according to the Eqs.(7)-(8)( the specific enthalpy is obtained from the data in the water and water vapor table fitting to get a pressure range of functional relation), the specific enthalpy of superheated steam is the dependent variable of pressure and temperature. In the equations, the density of water is a constant factor, it is determined by the ideal gas state equation. Therefore, the relevant thermodynamic parameters can be written as a function of pressure or temperature. The ratio of water volume to vessel volume( at the initial charging moment )and initial pressure are know, the hourly variation curves of pressure in the vessel under different conditions during the process of charging is obtained by simulation calculation.

The influence of different thermal steam parameters on the thermal characteristics of the steam accumulator is analyzed by using the above method of mathematical modelling approach in the process of charging, the following two factors are mainly considered: the steam pressure and steam flow.

\subsubsection{Steam accumulator variable steam pressure and constant steam flow}

Simulate the process of charging with saturated steam (the pressure is varied from $1 \mathrm{MPa}$ to $6 \mathrm{MPa}$ ). The constant initial pressure of the steam accumulator of $600 \mathrm{kPa}$ is adopted, the steam flow in the process of charging is $3 \mathrm{~kg} / \mathrm{s}$, maintain the 
heat steam flow constant, the hourly pressure change in the heat accumulator is shown in Fig.2, using different saturation pressure during the process of charging.

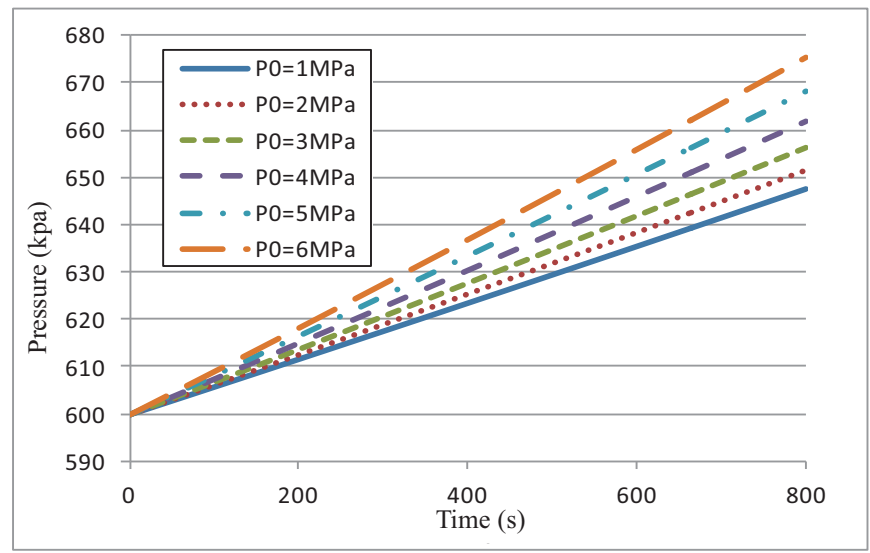

Fig.2. Calculated pressure change in the steam accumulator charged with the constant inlet steam flow

Heat steam enters the water space, and its condensation heat transfer to liquid saturated water, part of the condensation heat used to improve the parameters of the water itself, and the other part is used for the vaporization of water. The higher the saturated steam pressure, the more energy released during the process of condensation for saturated water with the same pressure, and speed up the evaporation of water and the heat storage of saturated water, therefore, the pressure inside the vessel is rising fast. With the charge of heat, energy stored in the vessel in the form of high pressure saturated water, the pressure in the vessel at the end of the charge must be lower than thermal steam pressure.

\subsubsection{Steam accumulator variable steam flow and constant steam pressure}

In actual operation process, after the steam source supply to the consumer, the remaining steam enters the steam accumulator for charging, due to the change of the consumer's demand, the steam inflow the accumulator will change too. The result of the steam accumulator operation (when simulating the linear change of steam flow during the process of charging) is shown in Fig. 3, the steam pressure during the process of charging is a constant (i.e.1Mpa), and the initial steam flow is $3 \mathrm{~kg} / \mathrm{s}$. With the increase of the flow rate, the pressure inside the vessel is increased, so the schematic is a curve.

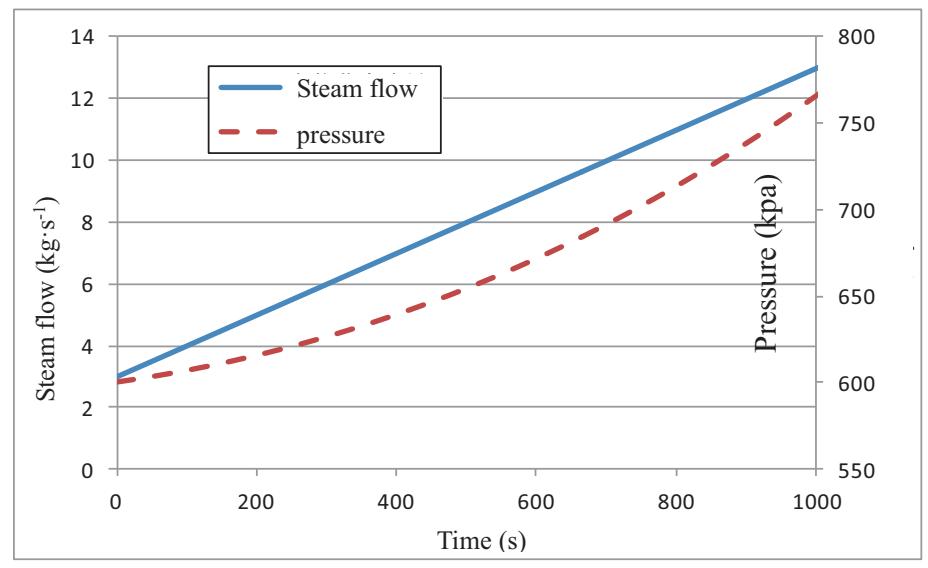

Fig.3. linear variation of steam flow during the process of charging 
In the actual process of charging, the change of the steam source and the steam using side can affect the inlet steam parameters of the steam accumulator, the flow and pressure of the steam may change at the same time, and it is not possible to follow the simple linear change. Therefore, the pressure curve of the steam accumulator operation during the process of charging is usually irregular.

\subsection{Characteristics of discharging process of steam accumulator}

When the steam accumulator is discharged, the released steam come from the steam space in the current time, the steam parameter of the outlet is equal to the steam parameter of the steam space at the moment. The pressure during the process of discharging decreases, so the steam parameters are changed hourly[12]. The time step is $\Delta t^{\prime}$, the volume of the steam accumulator is $V$,suppose the volume of water at a time during the process of discharging is $V_{1}^{\prime}, p_{1}^{\prime}$ and $T_{1}^{\prime}$ are the pressure and temperature, respectively, $h_{w 1}{ }^{\prime}$ and $h_{s 1}{ }^{\prime}$ are the specific enthalpy of water and steam, respectively, $\rho_{w 1}{ }^{\prime}$ and $\rho_{s 1}{ }^{\prime}$ are the density of water and steam, respectively; After $\Delta t^{\prime}$ hours of discharging, the volume of water is $V_{2}^{\prime}$, pressure and temperature are $p_{2}{ }^{\prime}$ and $T_{2}^{\prime}$, respectively, the specific enthalpy of water and steam are $h_{w 2}{ }^{\prime}$ and $h_{s 2}{ }^{\prime}$, respectively, the density of water and steam are $\rho_{w 2}{ }^{\prime}$ and $\rho_{s 2}{ }^{\prime}$, respectively. Because the time step is very short, it can be considered that the outlet steam flow is constant(i.e. $\left.m_{0}{ }^{\prime}\right)$ in the process of $\Delta t^{\prime}$ hours discharging, and the specific enthalpy of the outlet steam in this period is also a constant, i.e. $\left(h_{s 1}{ }^{\prime}+h_{s 2}{ }^{\prime}\right) / 2$.

The following equation is established after the steam accumulator discharge $\Delta t^{\prime}$ time:

Mass balance equation:

$$
\rho_{s 1}{ }^{\prime}\left(V-V_{1}^{\prime}\right)+\rho_{w 1}{ }^{\prime} V_{1}^{\prime}=\rho_{s 2}{ }^{\prime}\left(V-V_{2}^{\prime}\right)+\rho_{w 2}{ }^{\prime} V_{2}^{\prime}+m_{0}{ }^{\prime} \Delta t^{\prime}
$$

Energy balance equation:

$$
\begin{aligned}
\rho_{s 1}{ }^{\prime} h_{s 1}{ }^{\prime}\left(V-V_{1}{ }^{\prime}\right)+\rho_{w 1}{ }^{\prime} h_{w 1}{ }^{\prime} V_{1}^{\prime} & =\rho_{s 2}{ }^{\prime} h_{s 2}{ }^{\prime}\left(V-V_{2}{ }^{\prime}\right)+\rho_{w 2}{ }^{\prime} h_{w 2}{ }^{\prime} V_{2}{ }^{\prime}+ \\
& m_{0}{ }^{\prime} \frac{h_{s 1}{ }^{\prime}+h_{s 2}{ }^{\prime}}{2} \Delta t^{\prime}
\end{aligned}
$$

In Eqs.(9) (10),the temperature and density parameter of water and steam can be obtained by the change of the corresponding state pressure, the specific enthalpy of saturated water and saturated steam can be calculated according to Eqs.(7)-(8),the specific enthalpy of superheated steam is the dependent variable of pressure and temperature. The density of water is constant in the equations, the density of water vapor is determined by the ideal gas state equation. Therefore, the relevant thermodynamic parameters can be written as a function of pressure or temperature. The ratio of water volume to vessel volume at the initial discharging moment and initial pressure are know, the hourly variation curves of pressure in the vessel under different conditions during the process of discharging is obtained by simulation calculation.

The outlet of the accumulator is connected with the consumer, the process of discharging is controlled according to consumers' requirement, and it is often used in two modes: mass flow control and pressure control. The influence of different control modes on the thermal characteristics of the steam accumulator is analyzed by using the above method of mathematical modelling approach in the process of discharging (i.e. outlet flow control mode and pressure control mode).

\subsubsection{Outlet flow control mode}

Outlet flow control mode, i.e. controlling the change of the outlet steam flow, in this paper, simulated the linear variation of the outlet flow and calculated hourly variation curve of relative parameters in the vessel that based on regard $m_{0}$ as a function of the known time. The constant initial pressure of the charging process of $800 \mathrm{kPa}$ is adopted, control the steam 
flow rate from $3 \mathrm{~kg} / \mathrm{s}$ to start with time increasing linearly, then the pressure changing with time in the steam accumulator is shown in Fig. 4. With the increase of the outlet steam flow rate, the pressure decreasing rate of the steam accumulator is accelerated, the self - evaporation rate is also accelerated due to the pressure difference between saturated water and steam space, the hourly change of water level in the vessel is similar to pressure [13].

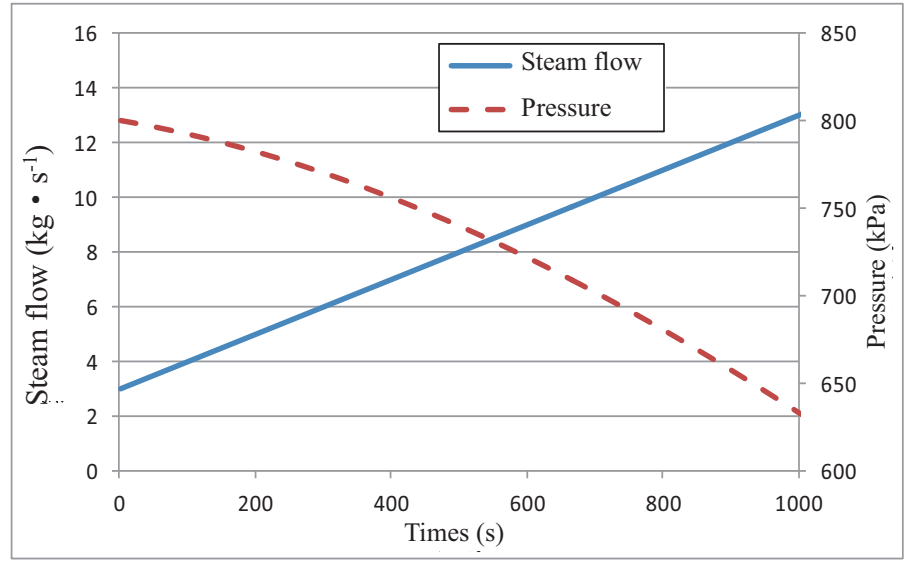

Fig.4. linear variation of outlet steam flow during the process of discharging

\subsubsection{Pressure control mode}

Pressure control mode, i.e. controlling the change of the outlet steam pressure of the accumulator, in this paper, simulated the operation of steam accumulator under the condition of simple linear variation of the outlet pressure, hourly variation curve of water quantity and outlet steam flow can be obtained by taking certain accumulator sliding pressure rate, and the total amount of steam released can be obtained by the flow integral. Simulation results of using the pressure control mode in the process of discharging are shown in Fig. 5. The decreasing rate of pressure over time is same, but the initial pressure in the range of $0.8 \mathrm{MPa} \sim 1.3 \mathrm{MPa}$ has to take a different value (as shown in Fig. 5 (a)), the outlet steam flow changing over time in the steam accumulator is shown in Fig. 5 (b).

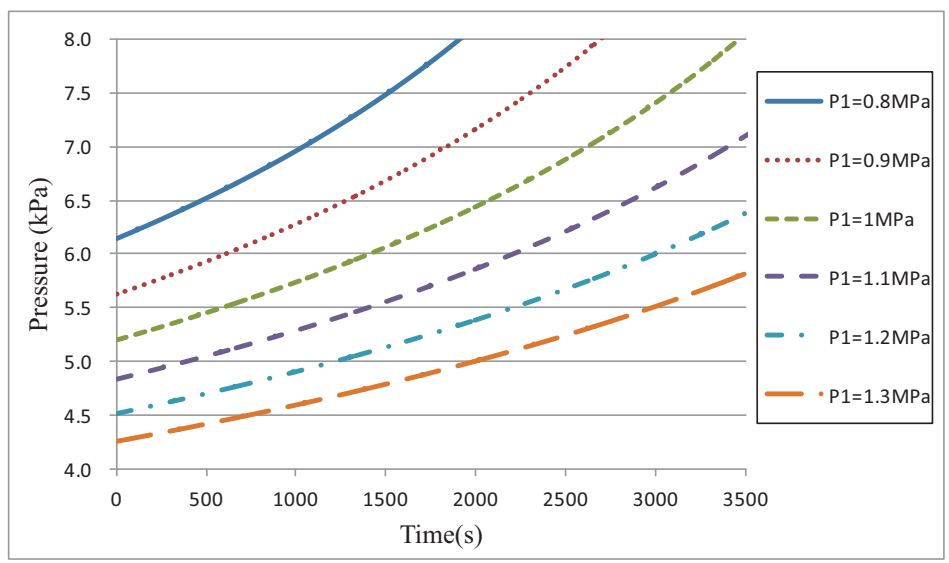

(a) Linear variation by controlling pressure 


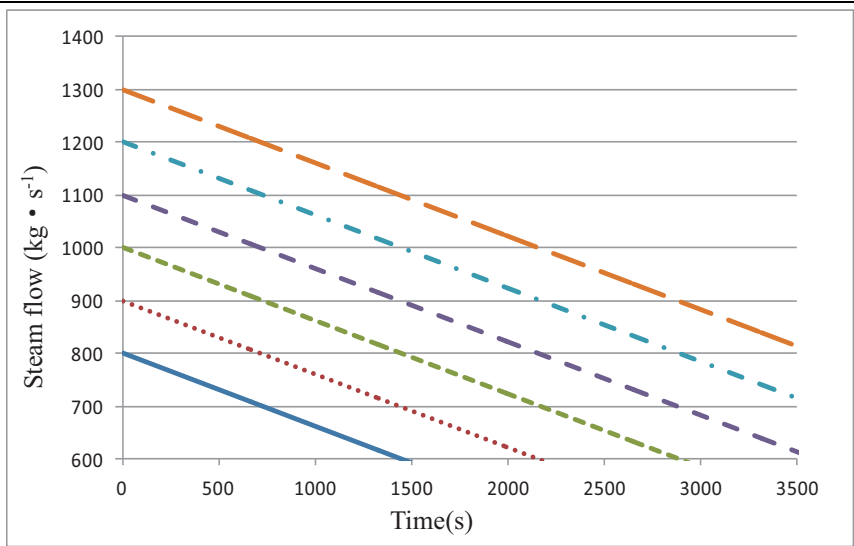

(b) Change of outlet steam flow in accumulator

Fig. 5 Linear variation of outlet steam pressure during the process of discharging

With the pressure in the vessel decreases, the outlet steam flow will gradually increasing and the rate of growth is accelerating. Analyzing the relationship between the specific enthalpy of saturated water and the corresponding saturation pressure can know that the slope of specific enthalpy change with pressure curve increases with the decrease of pressure, therefore, with the process of discharging, the energy released by the unit pressure decreases is gradually increasing and can make more saturated water evaporation, which can explain the phenomenon that the outlet steam flow increases with the pressure decreases[3]. The higher the initial pressure (which is given), the smaller the outlet steam flow at the same time, this can also explained by the relationship curve between the specific enthalpy of saturated water and the corresponding saturation pressure. Therefore, the released energy of the steam accumulator is related to the initial pressure and the working pressure difference, The higher the initial release pressure, the less the amount of steam released by the same work differential pressure.

\section{Conclusions}

In this paper, established the mathematical model of the steam accumulator depending on analyzing thermodynamics of the steam accumulator charging and discharging and assuming the water and steam in the vessel are in thermal equilibrium, according to the mathematical model, the process of charging and discharging are simulated respectively and the dynamic characteristics of charging and discharging are obtained. Through the analysis of the simulation results, the following conclusions can be drawn:

(1)The pressure in the vessel is increased by time during accumulator charging;

(2) The regenerative rate of the steam accumulator is related to the steam flow and steam pressure, the greater the steam flow and the higher the pressure, the greater the regenerative rate of the accumulator, and the less time needed to achieve the same hot filling pressure.

(3) The steam pressure, temperature and other parameters of the steam accumulator, which are released during discharging, are decreased by time, but outlet steam flow rate increases;

(4) The released energy of the steam accumulator is related to the initial pressure and working pressure difference, the

\section{References}

1. E.S. Xu, W. Gao, F. Xu et al. Simulation of Dynamic Characteristics of Steam Accumulators in the Badaling Solar Power Tower Plant, Applied Chinese Journal of Electrical Engineering 32 (8) (2012) 112-117.

2. X. Li, T.Y. Zhu, X.Y. Xu et al. Simulation of thermal storage system for 1MW solar power tower plant, Applied Journal of solar energy 32 (5) (2011) 632-638.

3. C.L. Gong, X.F. Liu et al. Thermo-hydraulic Feature Analysis of Steam Accumulator Operation, Applied Journal of Wuhan automobile industry university 18 (3) (1996) 73-76. 
4. X.F. Liu, C.L. Gong, S.J. Liu. Analytical calculation and experimental study on temperature rising process of steam accumulator, Applied Journal of solar energy 19 (1) (1998) 102-104.

5. Z.F. Zhao, L.J. Liu. Analysis on operation characteristics of steam accumulator, Applied Qinghai electric power 30 (4) (2011) 9-12.

6. Z.Q. Yang. Experimental study on the characteristics of steam accumulator charging and discharging, Applied Harbin Engineering University (2012).

7. Ismail M, Shah MH, Kamal MAA et al. Research Work on Steam Accumulator in Palm Oil Mill. European Journal of Scientific Research, 2009; 37(4): 628-640.

8. Stevanovic VD, Maslovaric B, Prica S. Dynamics of steam accumulation. Applied Thermal Engineering, 2012; 37: 73-79.

9. Shnaider DA, Divnich PN,Vakhromeev IE. Modeling the Dynamic Mode of Steam Accumulator. Automation and Remote Control, 2010; 71(9): 1994-1998.

10. X. Sun, L.M. Xu, Q. Wu. MATLAB7.0 basic tutorial, Beijing: Tsinghua University press (2005).

11. H.T. Le. Study on Modeling and Dynamic Simulation of Lithium Bromide Absorption Heat Pump, Master degree thesis of North China Electric Power University (2009).

12. Fengwu Bai, Chao Xu. Performance analysis of a two-stage thermal energy storage system using concrete and steam accumulator. Applied Thermal Engineering, 2011; 31: 2764-2771.

13. Hahne E, Chen Y. Numerical study of flow and heat transfer characteristics in hot water stores. Solar energy, 1998; 64(1-3): 9-18. 